GJ Hubert1, F Kraus', N Hubert1, V Zietemann', C Maegerlein², S Platen ${ }^{3}$, H-U Kain ${ }^{4}$, PMW Bath5 ${ }^{5}$ B Friedrich², T Witton-Davies ${ }^{6}$, HJ Audebert ${ }^{7}$, RL Haberl1

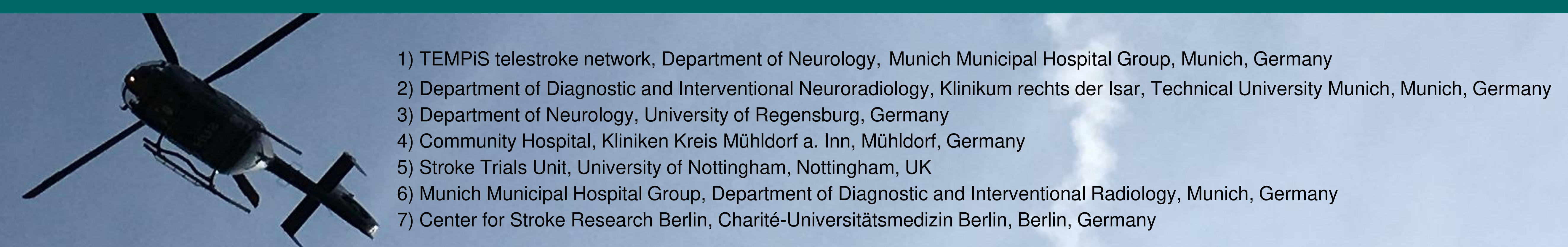

\section{Background and Aims:}

Endovascular treatment (EVT) for stroke patients with large vessel occlusion

a) requires high expertise,

b) demands fast treatment, and

c) should be available to all eligible stroke patients throughout the country.

Rural areas are underserved worldwide. The aim is to set up a network service that meets all three above mentioned requirements for EVT.

\section{Methods:}

The comprehensive stroke center sets up a team of neurointerventionalists and assistant staff to perform EVT in provincial hospitals connected to a telestroke network (TEMPiSGermany). In case of telemedically identified EVT candidates, the team will be flown to the hospital with an exclusive network helicopter. Meanwhile, the patient will be prepared for intervention in local angiography suite. After treatment patient will stay on local stroke unit for further treatment. Special material (stentretriever, aspiration catheters, etc.) will be brought by the team for each individual case. Data for concept development were obtained from TEMPiS-EVT-registry.

\section{Results:}

11 rural hospitals participate. 257 endovascular treatments are expected/year. Median delay (decision-groin puncture) is estimated to be reduced by 100 minutes compared to secondary transfer of patients. EVT team comprises 5 neuroradiologists and 5 assistant staff members from 2 comprehensive stroke centers in Munich. Service is provided 26 weeks/year starting 01/02/2018. Patients in "non-flying" weeks are transferred to closest comprehensive stroke center and will serve as control group for evaluation of the concept.

\section{Conclusion:}

Novel health care concepts need to be developed and evaluated for EVT in rural areas.

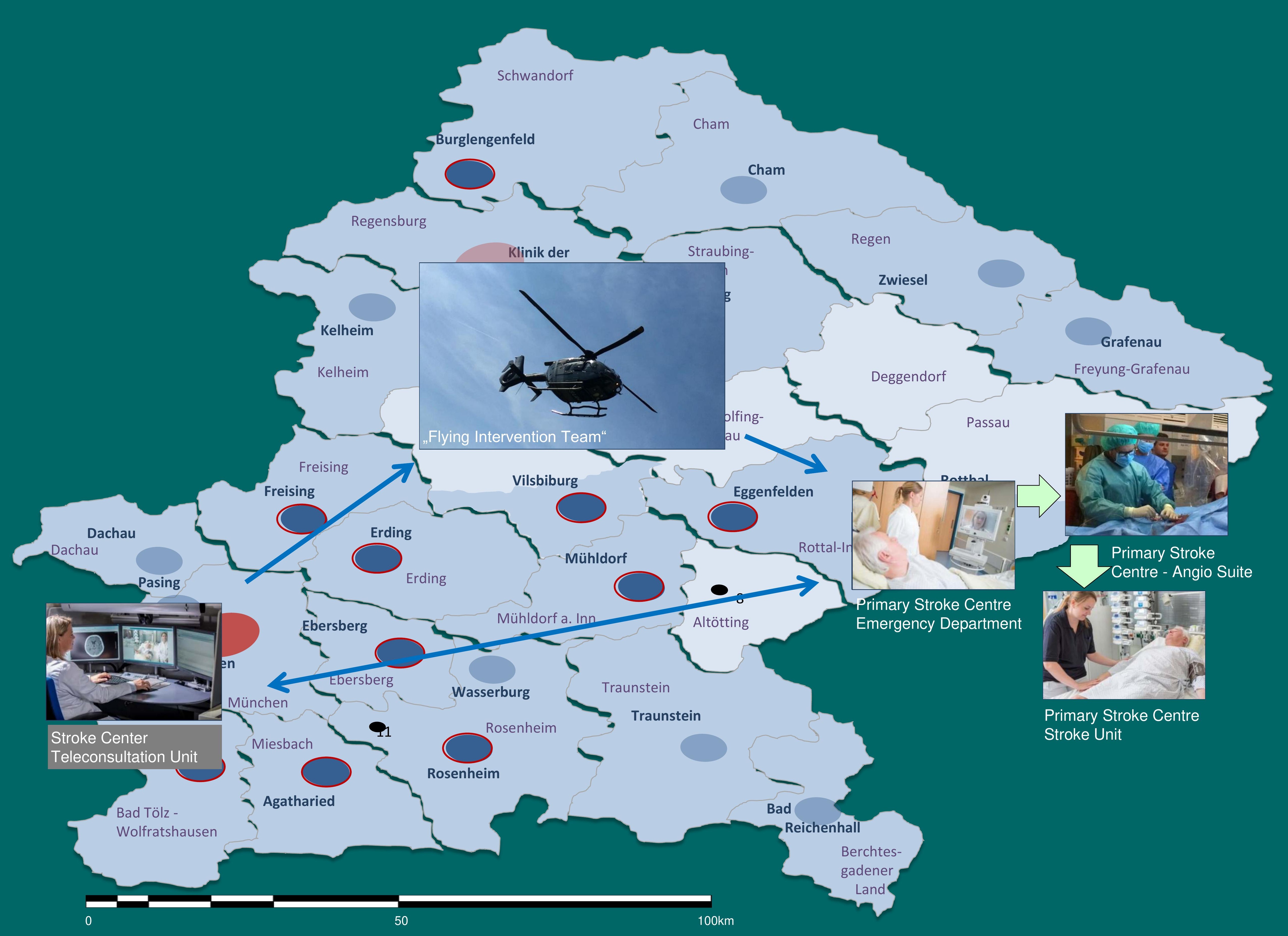

\section{TEMPiS}

\section{Telemedical stroke network}

TEMPiS is a telestroke network that consists of 2 centers and 21 attached regional spoke hospitals. It covers a region of 2.4 million inhabitants, an area of $19.000 \mathrm{~km}^{2}$, with a population density of $128 / \mathrm{km}^{2}$. Teleconsultation via videoconference and digital imaging transfer supports acute decisions e.g. on rt-PA administration or indication for endovascular treatment.

The two centres provide regular training sessions for the multidisciplinary teams of all hospitals. Standard operating procedures (SOPs) for the network were setup and are regularly renewed. Internal registries allow close quality control of the network.
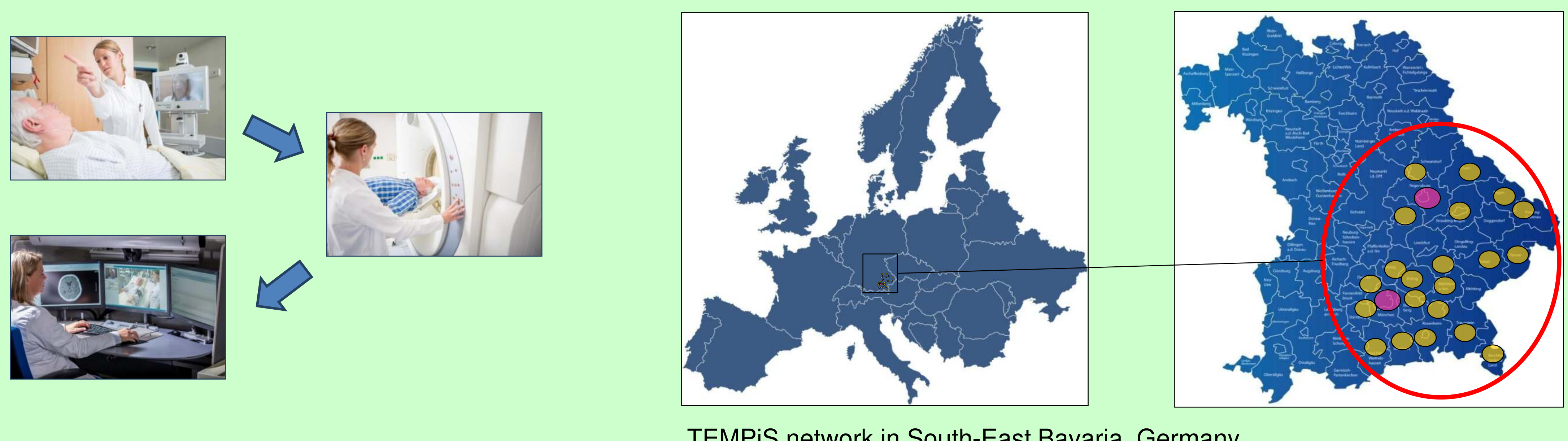

TEMPiS network in South-East Bavaria, Germany Centres: red, telestroke units: yellow
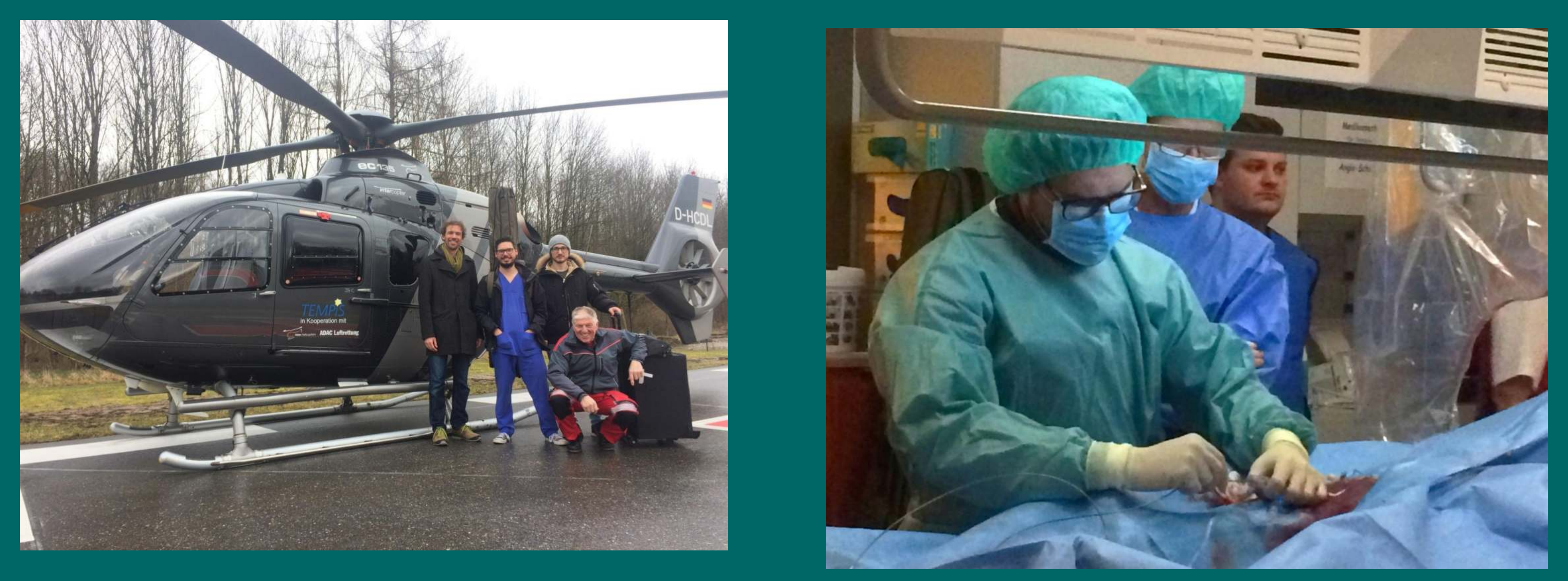

Contact: gordian.hubert@klinikum-muenchen.de www.tempis.de
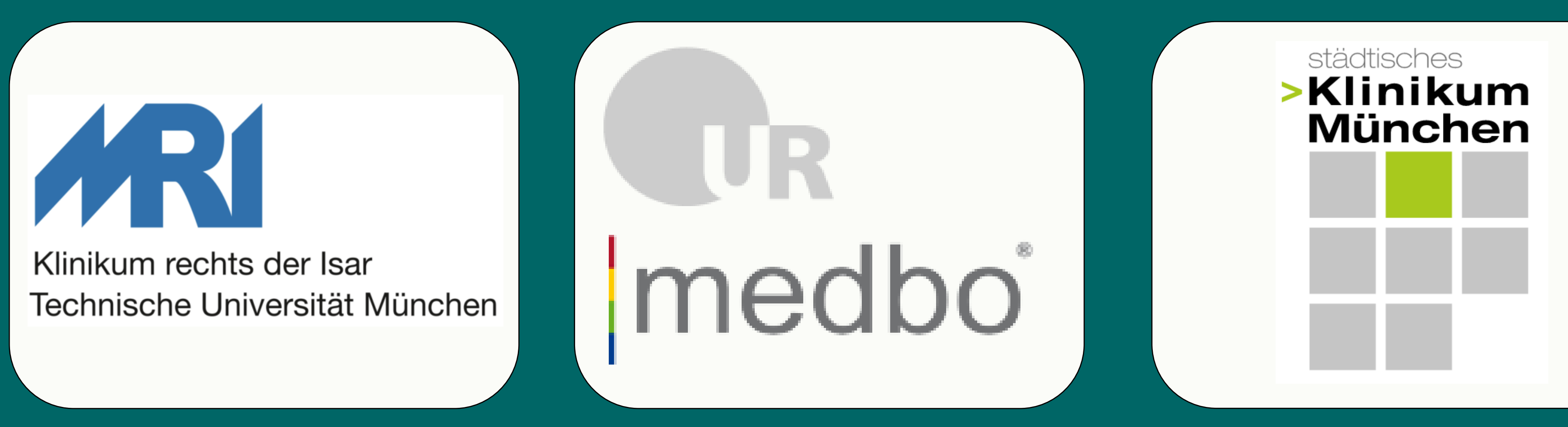